\title{
Oligomers in the Early Stage of Biogenic SOA Formation and Growth
}

Katherine J. Heaton, Matthew A. Dreyfus, Shenyi Wang and Murray V. Johnston*

Department of Chemistry and Biochemistry, University of Delaware, Newark, DE 19716

*Corresponding author: phone (302)831-8014, fax (302)831-6335, Email mvj@udel.edu

Number of pages: 11

Number of Tables: 9 
Table S1. M/z values of ions produced by common fragmentation routes.

\begin{tabular}{|c|c|c|c|c|c|c|c|}
\hline dimer MW & $\mathrm{M}-\mathrm{OH}$ & $\mathrm{M}-\mathrm{COOH}$ & $\mathrm{M}-\mathrm{OOH}$ & $\mathrm{M}-\mathrm{H}_{2} \mathrm{O}$ & $\mathrm{M}-\mathrm{CHO}$ & $\mathrm{M}-\left(\mathrm{OOH} \& \mathrm{H}_{2} \mathrm{O}\right)$ & large fragment \\
\hline 292 & & & & & & & 291 \\
\hline 294 & & & & & & & 293 \\
\hline 298 & & & & & & & 297 \\
\hline 306 & & & & & & & 305 \\
\hline 308 & 291 & & & & & & 307 \\
\hline 310 & 293 & & & & & & 309 \\
\hline 312 & 295 & & & & & & \\
\hline 314 & 297 & & & & & & \\
\hline 320 & & & & & 291 & & \\
\hline 322 & 305 & & & & 293 & & 321 \\
\hline 324 & 307 & & 291 & & 295 & & 323 \\
\hline 326 & 309 & & 293 & & 297 & & \\
\hline 328 & & & 295 & & & & \\
\hline 330 & & & 297 & & & & \\
\hline 334 & & & & & 305 & & \\
\hline 336 & & 291 & & & 307 & & 335 \\
\hline 338 & 321 & 293 & 305 & & 309 & & 337 \\
\hline 340 & 323 & 295 & 307 & & & & 339 \\
\hline 342 & & 297 & 309 & & & 291 & \\
\hline 344 & & & & & & 293 & 343 \\
\hline 346 & & & & & & 295 & \\
\hline 352 & 335 & 307 & & & 323 & & 351 \\
\hline 354 & 337 & 309 & 321 & & & & 353 \\
\hline 356 & 339 & & 323 & 338 & & 305 & 355 \\
\hline 360 & 343 & & & & & 309 & \\
\hline \multicolumn{8}{|l|}{362} \\
\hline 366 & & 321 & & & 337 & & 365 \\
\hline 368 & 351 & 323 & 335 & & 339 & & 367 \\
\hline 370 & 353 & 325 & 337 & & & & \\
\hline 372 & 355 & & 339 & 354 & 343 & 321 & \\
\hline 374 & & & & & & 323 & \\
\hline 376 & & & 343 & & & & \\
\hline \multicolumn{8}{|l|}{378} \\
\hline 380 & & 335 & & & 351 & & 379 \\
\hline 382 & 365 & 337 & & & 353 & & \\
\hline 384 & 367 & 339 & 351 & & & & \\
\hline 386 & & & 353 & & & 335 & \\
\hline 388 & & 343 & 355 & 370 & & 337 & \\
\hline 390 & & & & & & 339 & \\
\hline \multicolumn{8}{|l|}{392} \\
\hline 394 & & & & & 365 & 343 & 393 \\
\hline 396 & 379 & 351 & & & 367 & & \\
\hline 398 & & 353 & 365 & & & & \\
\hline 400 & & 355 & 367 & & & & \\
\hline 402 & & & & & & 351 & \\
\hline 404 & & & & 386 & & 353 & \\
\hline 406 & & & & & & 355 & \\
\hline 408 & & & & & 379 & & 407 \\
\hline 410 & 393 & 365 & & & & & \\
\hline 412 & & 367 & 379 & & & & \\
\hline 416 & & & & & & 365 & \\
\hline 418 & & & & 400 & & 367 & \\
\hline 420 & & & & 402 & & & \\
\hline 422 & & & & 404 & 393 & & \\
\hline 424 & 407 & 379 & & & & & \\
\hline 426 & & & 393 & & & & \\
\hline 432 & & & & 414 & & & \\
\hline 436 & & & & & 407 & & \\
\hline
\end{tabular}




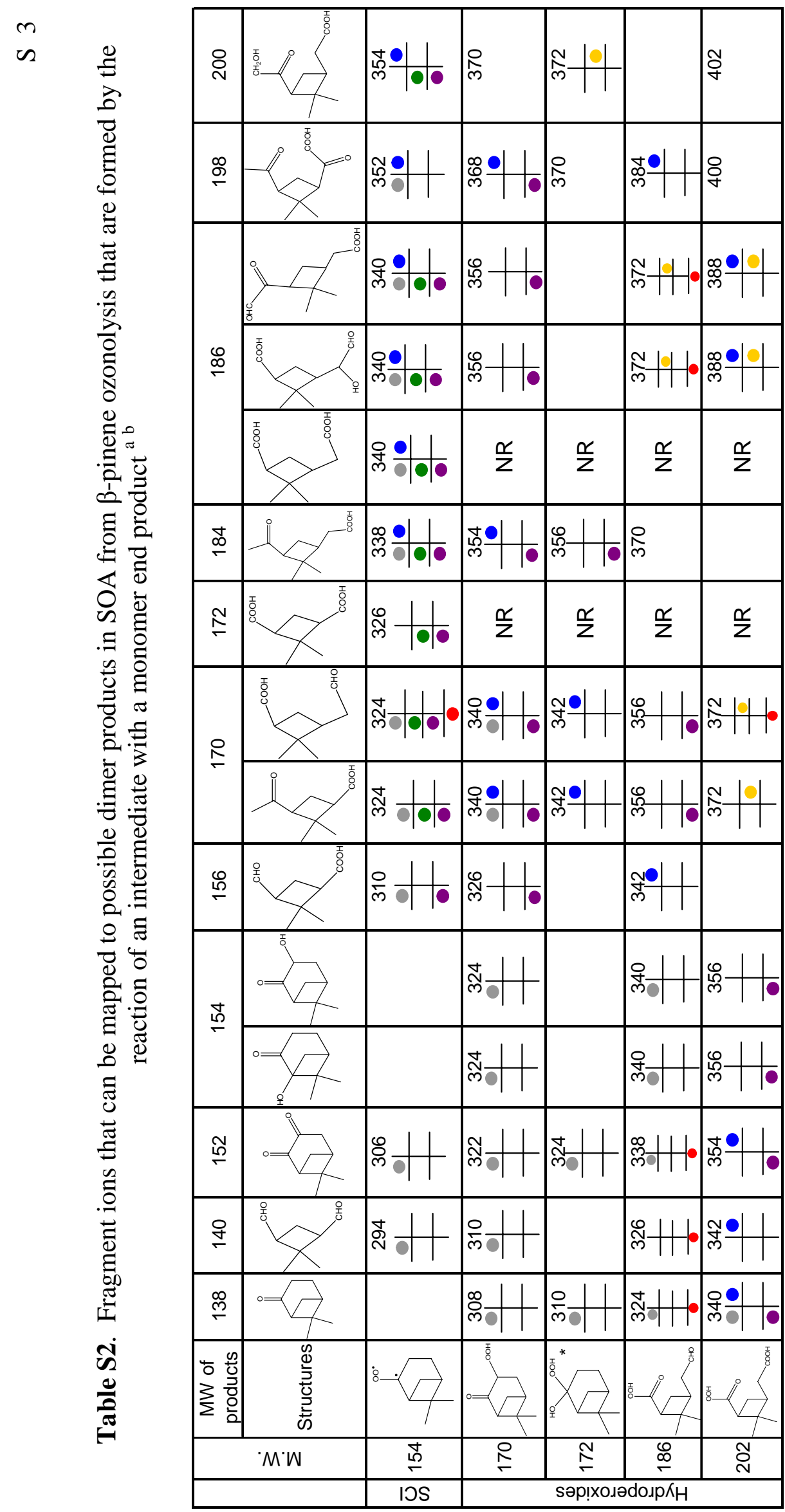

प๐

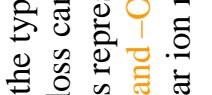

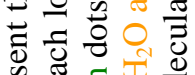

过

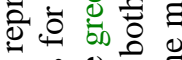

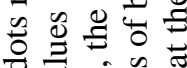

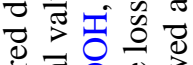

흥월

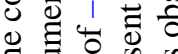

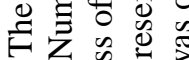

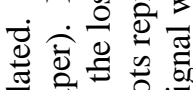

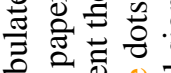

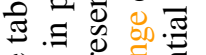

슴

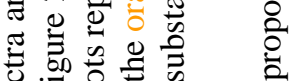

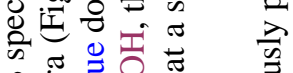

की

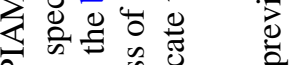

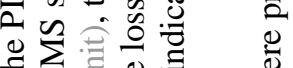

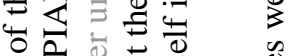

ธิ

का

N व

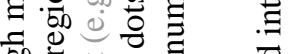

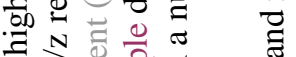

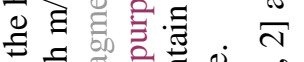

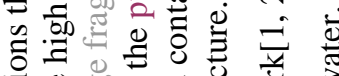

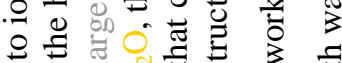

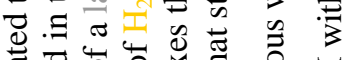

.

कै

8 O

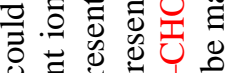

运完 $\frac{1}{0}$

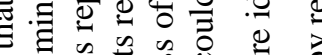

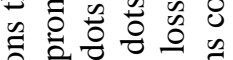

으요.

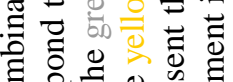

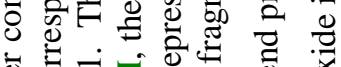

过的武氙

可类递

¿

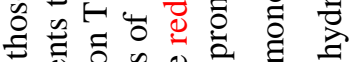

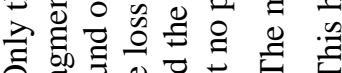

ठี 


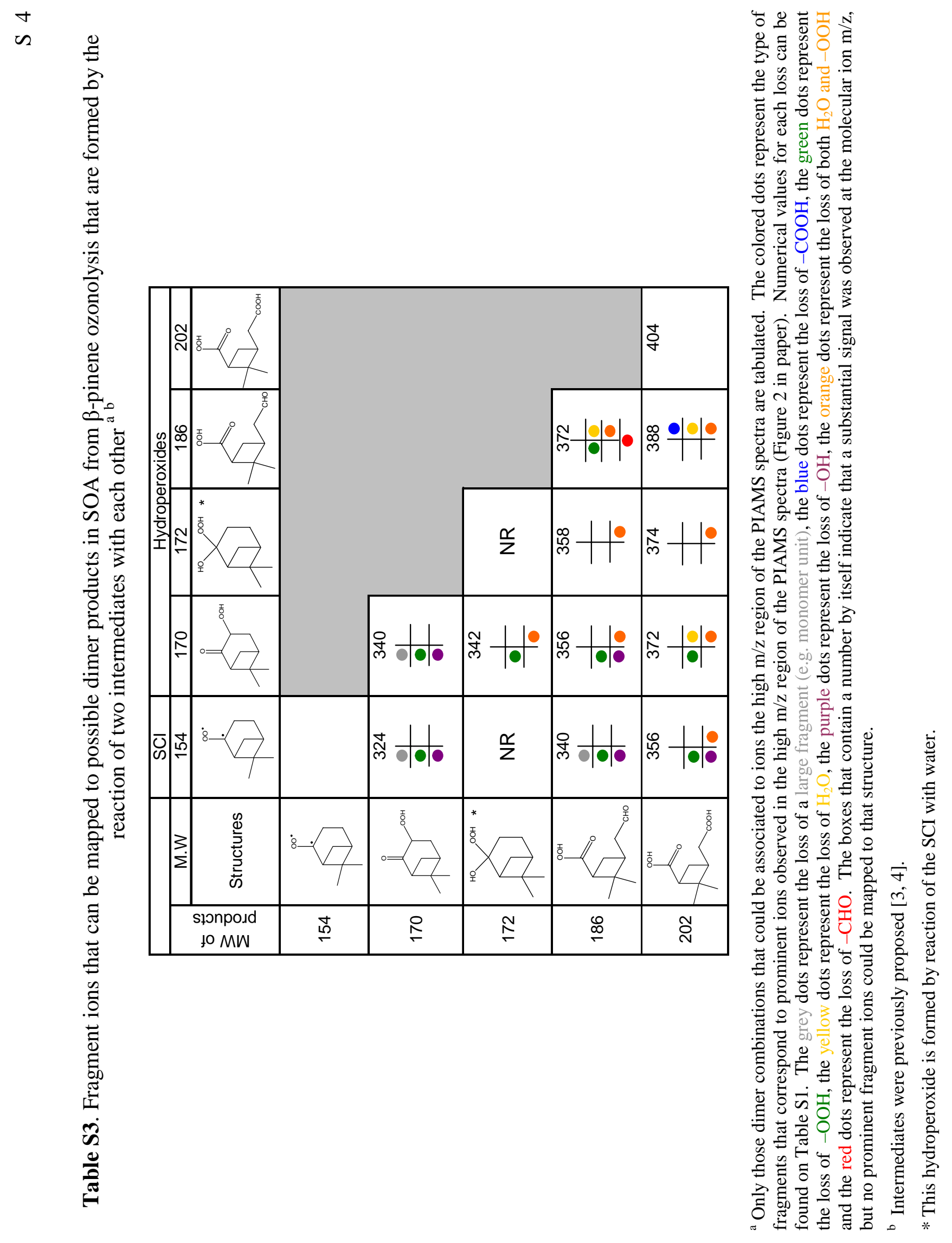


Table S4. Fragment ions that can be mapped to possible dimer products in SOA from $\Delta^{3}$-carene ozonolysis that are formed by the reaction of an intermediate with a monomer end product ${ }^{\mathrm{a} b}$

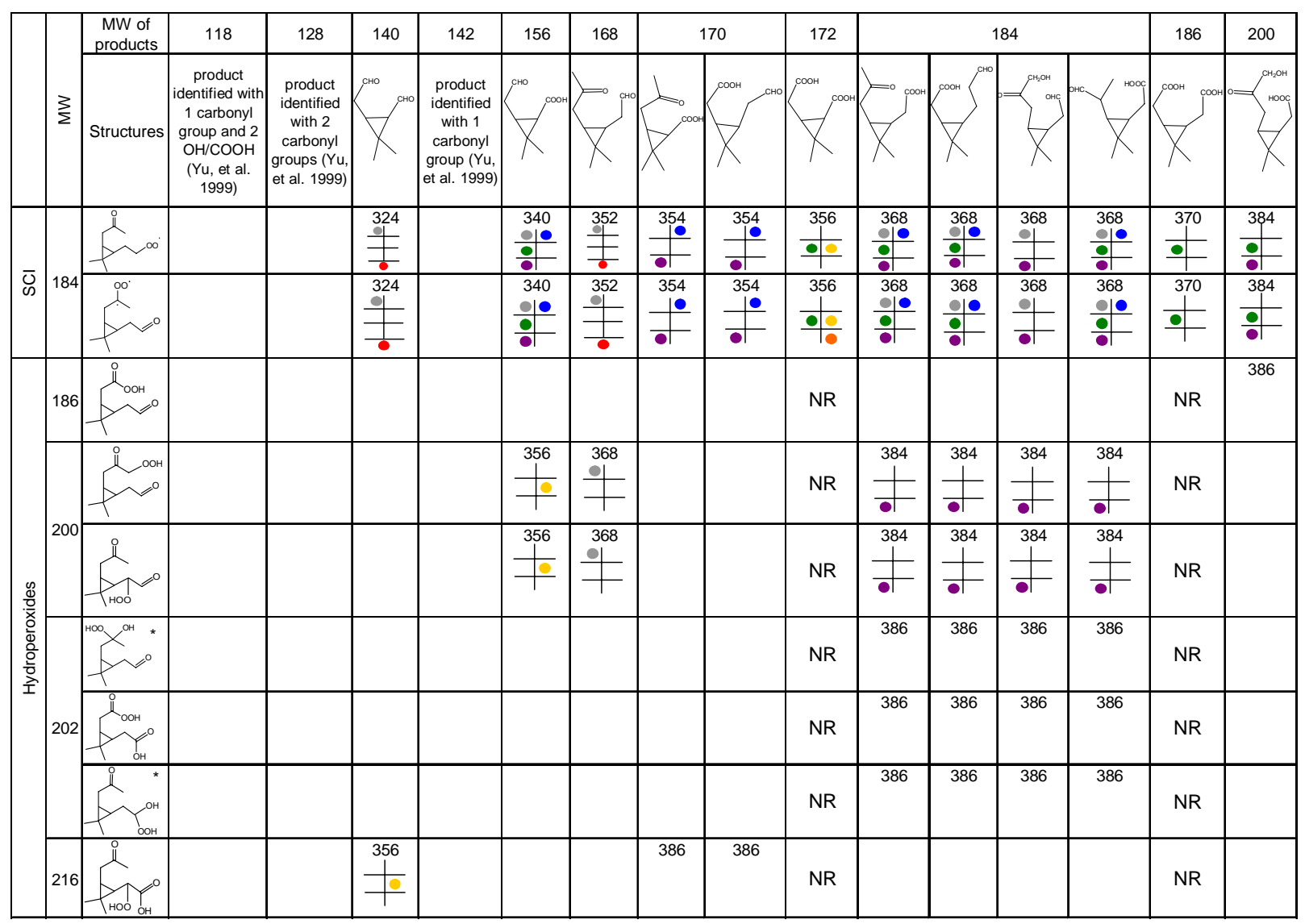

${ }^{a}$ Only those dimer combinations that could be associated to ions the high $\mathrm{m} / \mathrm{z}$ region of the PIAMS spectra are tabulated. The colored dots represent the type of fragments that correspond to prominent ions observed in the high $\mathrm{m} / \mathrm{z}$ region of the PIAMS spectra (Figure 2 in paper). Numerical values for each loss can be found on Table S1. The grey dots represent the loss of a large fragment (e.g. monomer unit), the blue dots represent the loss of $-\mathrm{COOH}$, the green dots represent the loss of $-\mathrm{OOH}$, the yellow dots represent the loss of $\mathrm{H}_{2} \mathrm{O}$, the purple dots represent the loss of $-\mathrm{OH}$, the orange dots represent the loss of both $\mathrm{H}_{2} \mathrm{O}$ and $-\mathrm{OOH}$ and the red dots represent the loss of -CHO. The boxes that contain a number by itself indicate that a substantial signal was observed at the molecular ion $\mathrm{m} / \mathrm{z}$, but no prominent fragment ions could be mapped to that structure.

$\mathrm{b}$ The monomer end products were identified in previous work[1,2] and intermediates were previously proposed [3, 4].

* This hydroperoxide is formed by reaction of the SCI with water. 
Table S5. Fragment ions that can be mapped to possible dimer products in SOA from $\Delta^{3}$-carene ozonolysis that are formed by the reaction of two intermediates with each other ${ }^{\mathrm{a}} \mathrm{b}$

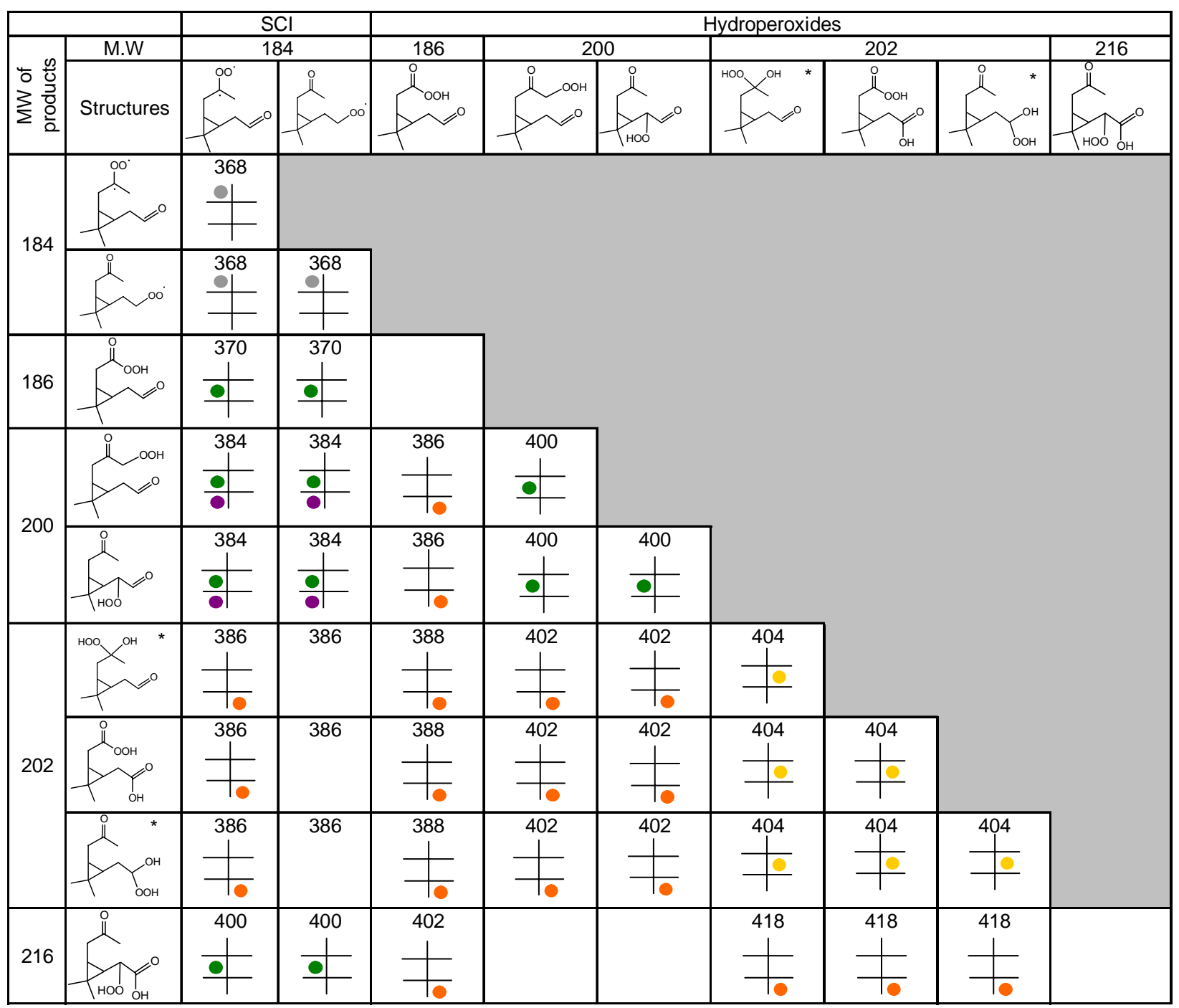

${ }^{a}$ Only those dimer combinations that could be associated to ions the high $\mathrm{m} / \mathrm{z}$ region of the PIAMS spectra are tabulated. The colored dots represent the type of fragments that correspond to prominent ions observed in the high $\mathrm{m} / \mathrm{z}$ region of the PIAMS spectra (Figure 2 in paper). Numerical values for each loss can be found on Table S1. The grey dots represent the loss of a large fragment (e.g. monomer unit), the blue dots represent the loss of $-\mathrm{COOH}$, the green dots represent the loss of $-\mathrm{OOH}$, the yellow dots represent the loss of $\mathrm{H}_{2} \mathrm{O}$, the purple dots represent the loss of $-\mathrm{OH}$, the orange dots represent the loss of both $\mathrm{H}_{2} \mathrm{O}$ and $-\mathrm{OOH}$ and the red dots represent the loss of $-\mathrm{CHO}$. The boxes that contain a number by itself indicate that a substantial signal was observed at the molecular ion $\mathrm{m} / \mathrm{z}$, but no prominent fragment ions could be mapped to that structure.

b Intermediates were previously proposed [3, 4].

* This hydroperoxide is formed by reaction of the SCI with water. 
Table S6. Fragment ions that can be mapped to possible dimer products in SOA from limonene ozonolysis that are formed by the reaction of an intermediate with a monomer end product ${ }^{\mathrm{a} b}$

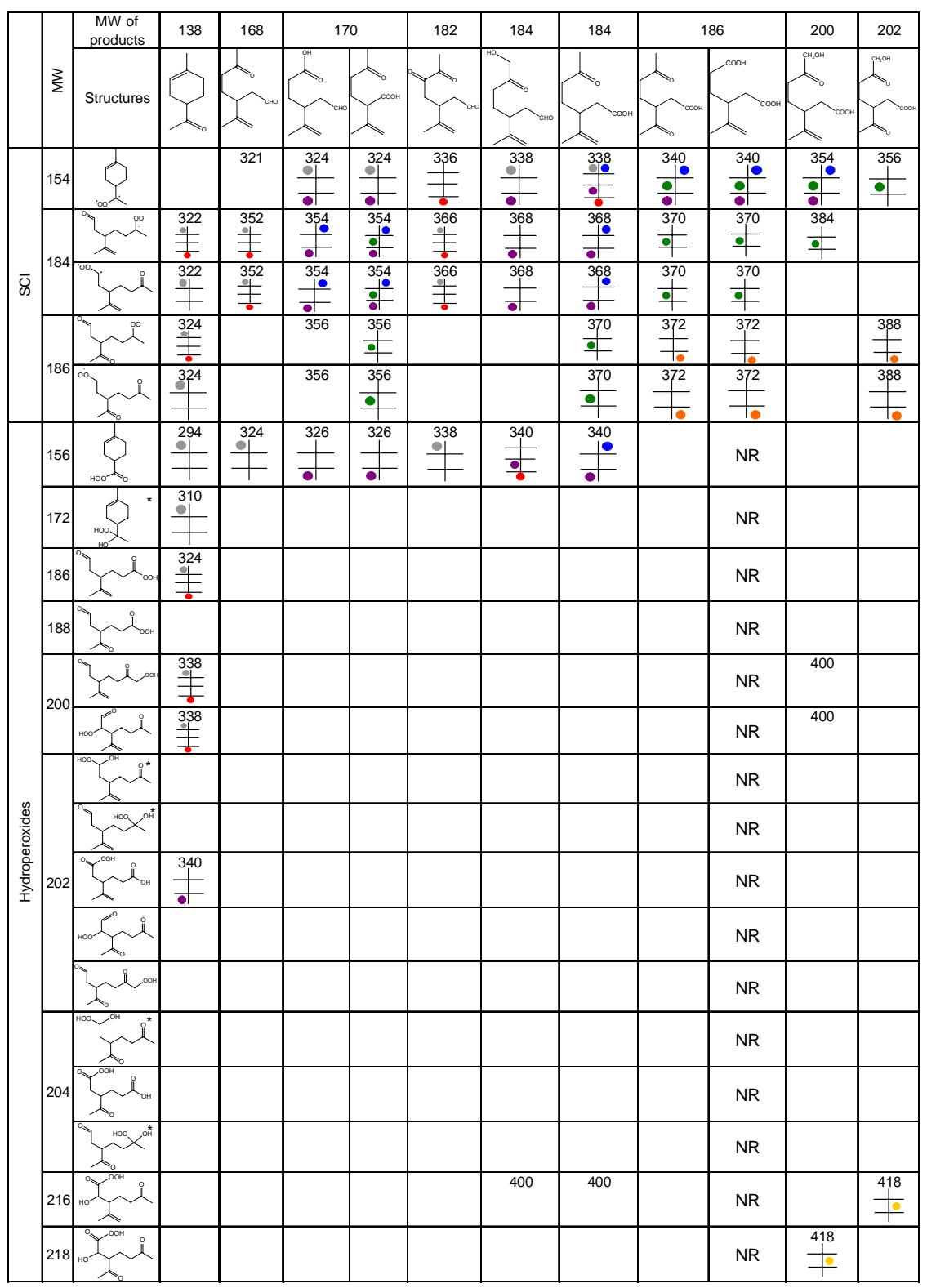

a Only those dimer combinations that could be associated to ions the high $\mathrm{m} / \mathrm{z}$ region of the PIAMS spectra are tabulated. The colored dots represent the type of fragments that correspond to prominent ions observed in the high $\mathrm{m} / \mathrm{z}$ region of the PIAMS spectra (Figure 2 in paper). Numerical values for each loss can be found on Table S1. The grey dots represent the loss of a large fragment (e.g. monomer unit), the blue dots represent the loss of $-\mathrm{COOH}$, the green dots represent the loss of $-\mathrm{OOH}$, the yellow dots represent the loss of $\mathrm{H}_{2} \mathrm{O}$, the purple dots represent the loss of $-\mathrm{OH}$, the orange dots represent the loss of both $\mathrm{H}_{2} \mathrm{O}$ and $-\mathrm{OOH}$ and the red dots represent the loss of $-\mathrm{CHO}$. The boxes that contain a number by itself indicate that a substantial signal was observed at the molecular ion $\mathrm{m} / \mathrm{z}$, but no prominent fragment ions could be mapped to that structure.

$\mathrm{b}$ The monomer end products were identified in previous work $[1,2]$ and intermediates were previously proposed [3, 4].

* This hydroperoxide is formed by reaction of the SCI with water. 
Table S7. Fragment ions that can be mapped to possible dimer products in SOA from limonene ozonolysis that are formed by the reaction of two intermediates with each other ${ }^{\mathrm{a} b}$

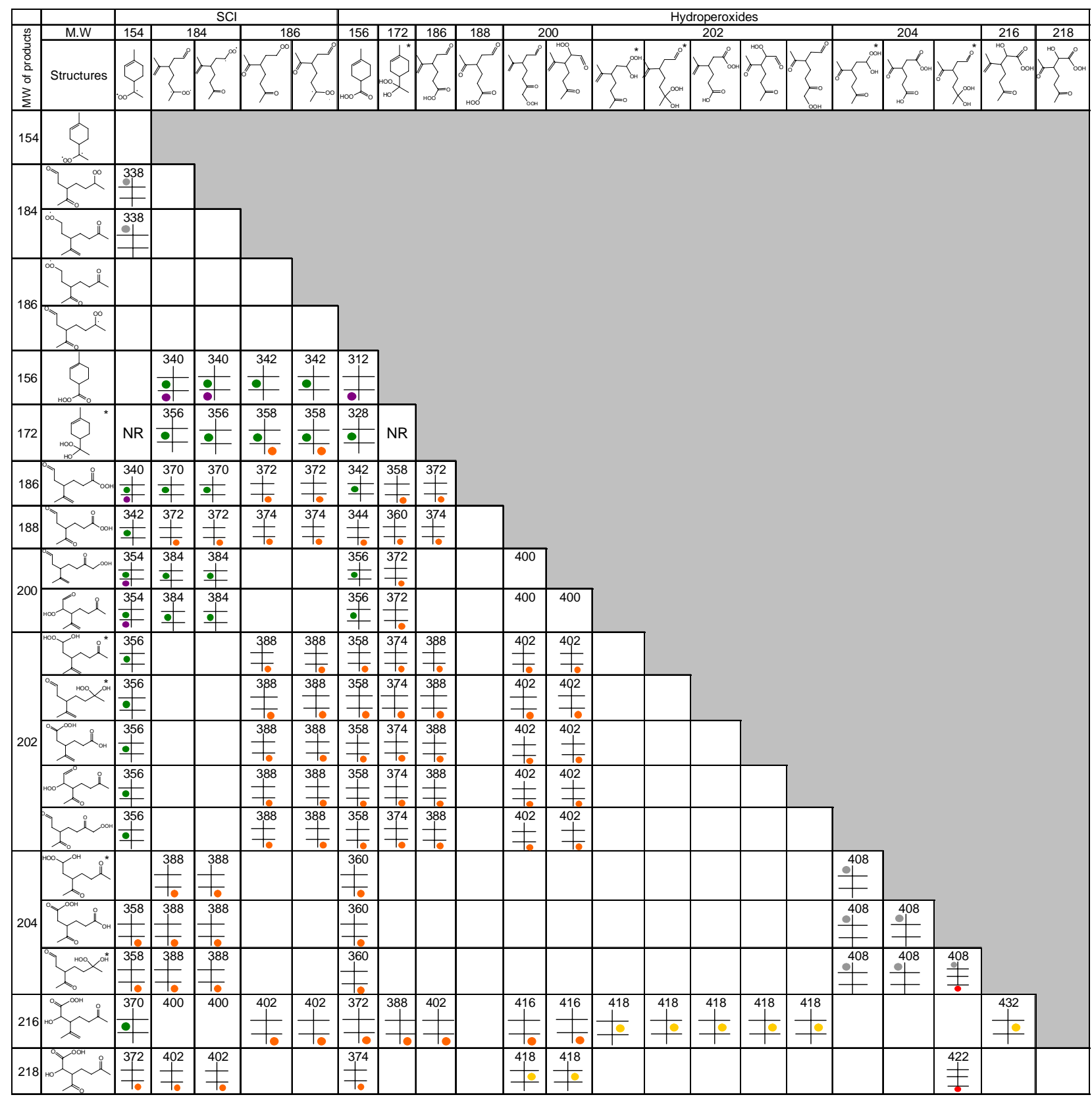

${ }^{\text {a }}$ Only those dimer combinations that could be associated to ions the high $\mathrm{m} / \mathrm{z}$ region of the PIAMS spectra are tabulated. The colored dots represent the type of fragments that correspond to prominent ions observed in the high $\mathrm{m} / \mathrm{z}$ region of the PIAMS spectra (Figure 2 in paper). Numerical values for each loss can be found on Table S1. The grey dots represent the loss of a large fragment (e.g. monomer unit), the blue dots represent the loss of -COOH, the green dots represent the loss of $-\mathrm{OOH}$, the yellow dots represent the loss of $\mathrm{H}_{2} \mathrm{O}$, the purple dots represent the loss of $-\mathrm{OH}$, the orange dots represent the loss of both $\mathrm{H}_{2} \mathrm{O}$ and $-\mathrm{OOH}$ and the red dots represent the loss of $-\mathrm{CHO}$. The boxes that contain a number by itself indicate that a substantial signal was observed at the molecular ion $\mathrm{m} / \mathrm{z}$, but no prominent fragment ions could be mapped to that structure.

b Intermediates were previously proposed [3, 4].

* This hydroperoxide is formed by reaction of the SCI with water. 


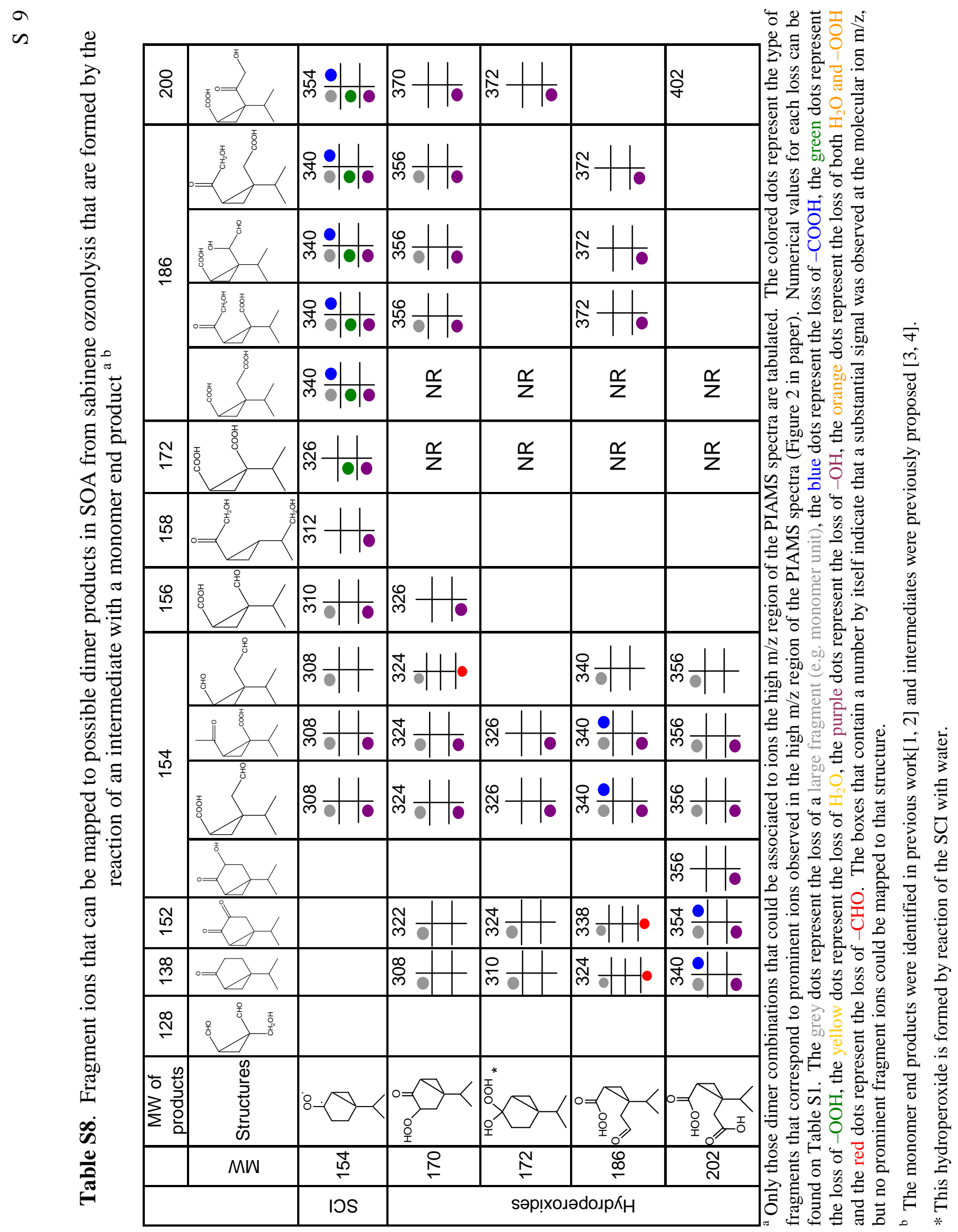


Table S9. Fragment ions that can be mapped to possible dimer products in SOA from sabinene ozonolysis that are formed by the reaction of two intermediates with each other ${ }^{\mathrm{a} b}$

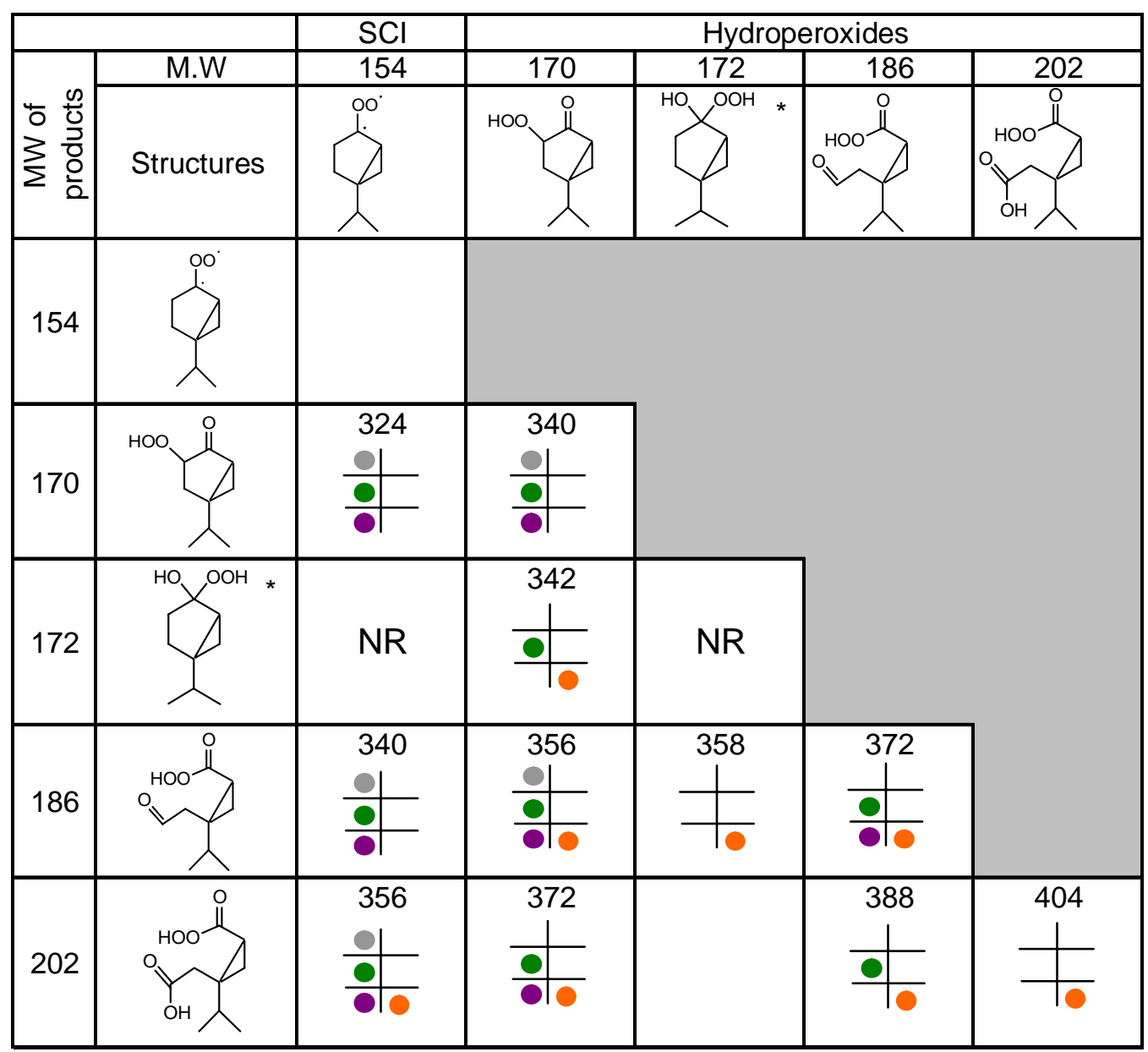

${ }^{a}$ Only those dimer combinations that could be associated to ions the high $\mathrm{m} / \mathrm{z}$ region of the PIAMS spectra are tabulated. The colored dots represent the type of fragments that correspond to prominent ions observed in the high $\mathrm{m} / \mathrm{z}$ region of the PIAMS spectra (Figure 2 in paper). Numerical values for each loss can be found on Table S1. The grey dots represent the loss of a large fragment (e.g. monomer unit), the blue dots represent the loss of $-\mathrm{COOH}$, the green dots represent the loss of $-\mathrm{OOH}$, the yellow dots represent the loss of $\mathrm{H}_{2} \mathrm{O}$, the purple dots represent the loss of $-\mathrm{OH}$, the orange dots represent the loss of both $\mathrm{H}_{2} \mathrm{O}$ and $-\mathrm{OOH}$ and the red dots represent the loss of -CHO. The boxes that contain a number by itself indicate that a substantial signal was observed at the molecular ion $\mathrm{m} / \mathrm{z}$, but no prominent fragment ions could be mapped to that structure.

b Intermediates were previously proposed [3, 4].

* This hydroperoxide is formed by reaction of the SCI with water. 


\section{References}

1. Warscheid, B. and T. Hoffman, Direct analysis of highly oxidised organic aerosol constituents by on-line ion trap mass spectrometry in the negative-ion mode. Rapid Communications in Mass Spectrometry, 2002. 16: p. 496-504.

2. Yu, J., D.R. Cocker III, R.J. Griffin, R.C. Flagan, and J.H. Seinfeld, Gas-Phase Ozone Oxidation of Monoterpenes: Gaseous and Particulate Products. Journal of Atmospheric Chemistry, 1999. 34: p. 207-258.

3. Jenkin, M.E., D.E. Shallcross, and J.N. Harvey, Development and application of a possible mechanism for the generation of cis-pinic acid from the ozonolysis of $\alpha$-and $\beta$ pinene. Atmospheric Environment, 2000. 34: p. 2837-2850.

4. Docherty, K.S., W. Wu, Y.B. Lim, and P.J. Ziemann, Contributions of Organic Peroxides to Secondary Aerosol Formed from Reaction of Monoterpenes with $\mathrm{O}_{3}$. Environmental Science and Technology, 2005. 39(11): p. 4049-4059. 